\title{
The effect of dietary iron intake on the development of iron overload among homozygotes for haemochromatosis
}

\author{
Min Tao* + and David L Pelletier \\ Division of Nutritional Sciences, Cornell University, Ithaca, NY, USA
}

Submitted 8 May 2007: Accepted 13 November 2008: First published online 6 February 2009

\begin{abstract}
Objective: To quantify the role of dietary Fe in total body Fe (TBI) accumulation among homozygotes for the HFE gene associated with haemochromatosis.

Design: A Monte Carlo model was built to simulate Fe accumulation based on findings from human feeding experiments and national dietary surveys. A hypothetical cohort of 1000 homozygotes with starting age 25 years was used in 39-year simulations. The impact of reducing dietary Fe intake on Fe accumulation was tested.

Results: In the baseline model without any dietary intervention, by age 64 , the percentage of males with $\mathrm{TBI}>10 \mathrm{~g},>15 \mathrm{~g}$ and $>20 \mathrm{~g}$ was $93 \cdot 2 \%, 49 \cdot 6 \%$ and $14.7 \%$, respectively. When the Fe intake of individuals in the cohort was reduced to $\leq 200 \%$ of the recommended dietary allowance (RDA), the corresponding percentages were $92 \cdot 0 \%, 40 \cdot 5 \%$ and $10 \cdot 2 \%$, respectively. The corresponding figures were $91 \cdot 0 \%, 40 \cdot 0 \%$ and $9 \cdot 3 \%$ for Fe defortification and $70 \cdot 3 \%, 21 \cdot 3 \%$ and $4 \cdot 1 \%$ when Fe intake was capped at $100 \%$ RDA. Similar trends were seen with sexes combined, although the impact of interventions was less. Sensitivity analysis revealed that the rate of Fe accumulation and the impact of dietary interventions are highly dependent on assumptions concerning Fe absorption rates.

Conclusions: Variation in Fe intake as currently observed in the USA contributes to variation in Fe accumulation among homozygotes, when continued over an extended period. Lifelong dietary habits and national fortification policy can affect the rate of $\mathrm{Fe}$ accumulation, although the magnitude of the effect varies by gender, the TBI level of interest and factors affecting the Fe absorption rate.
\end{abstract}

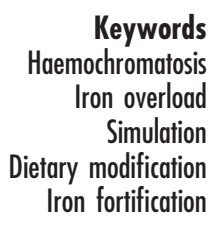

Since the discovery of a candidate gene for hereditary haemochromatosis $(\mathrm{HH})$ in 1996, HH has been found to be one of the most common autosomal recessive disorders in the US population, estimated to affect about one million people ${ }^{(1)}$. Among the mutations that have been reported, the prevalence of $\mathrm{C} 282 \mathrm{Y} / \mathrm{C} 282 \mathrm{Y}$ genotype is $0 \cdot 30 \%$ among non-Hispanic whites, $0 \cdot 06 \%$ among nonHispanic blacks and $0.03 \%$ among Mexican-Americans, with no gender differences ${ }^{(2)}$. The C282Y homozygote genotype is most closely associated with $\mathrm{HH}$, presenting in $67-95 \%$ of clinically diagnosed $\mathrm{HH}$ cases $^{(1-6)}$.

Clinically, $\mathrm{Fe}$ overload in individuals with $H F E$ gene mutations can lead to fatal complications such as liver cirrhosis and diabetes ${ }^{(7-11)}$. However, the severity of the disease varies greatly. It is well established that the majority of homozygotes will have increased transferrin saturation and serum ferritin $(\mathrm{SF})^{(3,12-16)}$, but the percentage of

$\dagger$ Correspondence address: Tower 400, $27000 \mathrm{~W} 11$ Mile Road, Southfield, MI 48034, USA. homozygotes who will develop clinical symptoms is still unclear. Factors influencing the progress of the disease remain poorly understood. A complex gene-gene interaction and gene-environment interaction is proposed ${ }^{(17,18)}$.

Some environmental factors are found to influence the manifestation of $\mathrm{HH}$, for example gender, age and blood donation $^{(18)}$. Dietary Fe may be another factor. A few feeding studies on Fe absorption among individuals with genetic mutations showed that the feedback control of $\mathrm{Fe}$ absorption was impaired in patients with $\mathrm{HH}^{(19-21)}$. Their absorption of both haem and non-haem Fe was higher than in normal individuals. Consistently, two studies suggested that higher dietary Fe intake may accelerate Fe accumulation in patients with $\mathrm{HH}^{(22,23)}$. Current recommendations on the management of $\mathrm{HH}$ recommend avoiding vitamin $\mathrm{C}$ and $\mathrm{Fe}$ supplements, but do not suggest control of dietary Fe intake ${ }^{(24)}$.

The purpose of the current paper is to present a Monte Carlo model that simulates the Fe accumulation process in homozygotes for $\mathrm{HH}$ and to use the model to estimate 
whether dietary modification can be used as an effective prevention and treatment for $\mathrm{HH}$.

\section{Research design and methods}

\section{Model overview}

We developed a Monte Carlo simulation model using @Risk 4.5 for Excel (Palisades Inc., Newfield, NY, USA). The model generated a cohort of 1000 homozygotes with HFE mutations. Each individual in the cohort is followed up from 25 to 64 years of age, unless death occurs. The process of Fe accumulation in the cohort was simulated. The simulation outcome was total body Fe (TBI) because, according to clinical observations, this is an indicator closely related to the development of specific clinical symptoms and fatal complications.

Figure 1 illustrates the biological framework of the simulation model. TBI in the model was composed of three components: (i) Fe in Hb; (ii) non-storage Fe in tissues; and (iii) storage Fe. The small amount of transport Fe in the plasma and extracellular fluid was neglected in the model. During an individual's life, TBI is a changing variable. As shown in Fig. 1, TBI at a certain time point $\left(t_{i+1}\right)$ in the model is a function of previous Fe status $\left(t_{i}\right)$ and Fe loss and Fe absorption during the time period between $t_{i}$ and $t_{i+1}$. Data sources used to define TBI at $t_{0}$ and parameters used to simulate $\mathrm{Fe}$ absorption and $\mathrm{Fe}$ loss during various time periods are listed in Table $1^{(25-32)}$. Model structure is described in detail below. The impact of reducing dietary Fe on Fe accumulation in the cohort was tested using the model.

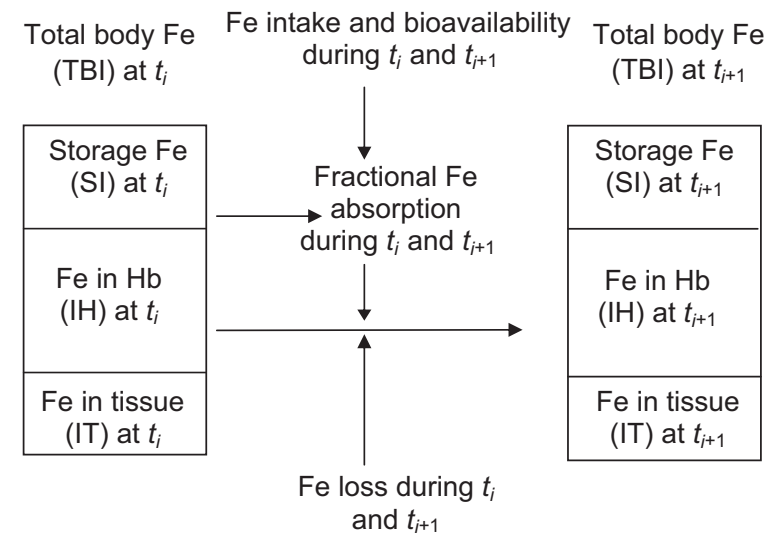

Fig. 1 Framework for simulating the dynamic change of iron status

\section{Model structure}

\section{Baseline status}

The simulation cohort started at age 25 years. To estimate each individual's TBI at $t_{0}$, their gender, height, weight, $\mathrm{Hb}$ and SF levels must be defined. The gender ratio and the distributions of height, weight and $\mathrm{Hb}$ for each gender group were calculated using data from the third National Health and Nutrition Examination Survey (NHANES III), since there is no evidence that homozygotes are different from non-homozygotes in values for these variables. However, SF levels differ between individuals with wild genotype and those with HFE mutations. Distributions of SF for males and females were based on SF levels of homozygotes between the ages of 20 and 29 years reported in a large cross-sectional survey ${ }^{(16)}$. Monte Carlo sampling was used to assign specific values for these variables to each individual in the model according to these distributions.

$\mathrm{Fe}$ in $\mathrm{Hb}$ was calculated based on $\mathrm{Hb}$ level and total blood volume estimated from weight and height, and nonstorage $\mathrm{Fe}$ in tissues estimated from body weight ${ }^{(33-35)}$. Storage Fe in tissues was calculated from SF level based on the linear relationship between SF and storage Fe among homozygotes. Data from three phlebotomy studies were used to quantify the linear relationship between SF and storage Fe in homozygotes ${ }^{(36-38)}$. This procedure generated the starting TBI level for each homozygote in the cohort.

Two time units were used to facilitate the simulation of changes in Fe status once individuals left baseline $\left(t_{0}\right)$ and were projected into the future: monthly and annual.

\section{Montbly updating}

Events simulated at monthly intervals include $\mathrm{Fe}$ absorption from food and supplements, daily Fe loss and menstruation. Within one simulation month, each individual was assumed to follow the same dietary intake. Since no evidence suggests the diet of homozygotes is different from that of non-homozygotes, data from the Continuing Survey of Food Intakes by Individuals (CSFII) 1994-96 were used to estimate meat, $\mathrm{Fe}$, $\mathrm{Ca}$ and ascorbic acid intakes for each gender and age group. Data were normalized using Cox-Box transformations, then ANOVA was used to estimate average dietary intake levels, intraand inter-individual variations ${ }^{(39)}$. Using Monte Carlo sampling, specific values were assigned to each individual according to these distributions. An individual's

Table 1 Sources of data used in the simulation model

\begin{tabular}{ll}
\hline Variable & \multicolumn{1}{c}{ Data source } \\
\hline Age, gender, height, weight, Hb level & NHANES III \\
Daily Fe, vitamin C, Ca and meat intake, Fe supplement usage during pregnancy & NHANES III, CSFII 1994-96, reference 25 \\
Daily Fe loss, Fe loss from menses, Fe requirement from pregnancy, blood donations & References 26-30, NHANES III \\
Fe absorption & References 19 and 21 \\
Mortality and fertility & References 31 and 32 \\
\hline
\end{tabular}

NHANES III, Third National Health and Nutrition Examination Survey; CSFII 1994-96, Continuing Survey of Food Intakes by Individuals. 
mean intake level of a nutrient for the month was assigned based on the average intake and inter-individual variance for his/her subgroup, then daily intake values were assigned based on each person's mean intake level and intra-individual variance. Linear equations were used to estimate the percentage of dietary Fe from fortification based on Fe intake in previous work ${ }^{(25)}$.

Fe absorption was determined by meal composition and the individual's Fe status. Monsen's model and the regression equation by Hallberg et al. were used to calculate bioavailable Fe based on the amount of $\mathrm{Fe}$, Fe absorption enhancers (ascorbic acid and meat) and $\mathrm{Fe}$ absorption inhibitors (Ca) contained in the diet ${ }^{(40,41)}$. In normal individuals, the feedback control of Fe absorption by Fe status is a critical part of Fe homeostasis. Feeding studies using homozygotes as subjects showed that although this process is greatly impaired, there is still a weak feedback control of Fe absorption by Fe status. After Fe bioavailability was calculated from meal composition, linear regression equations were used to predict the absorption rates of haem and non-haem Fe adjusted to each individual's Fe store. Data reported by Bezwoda et al. and Lynch et al. were used to build the regression model $^{(19,21)}$. The amount of Fe absorbed was calculated using Fe intake and Fe absorption rates and was assumed to be the amount of Fe that can be utilized in the body.

Loss of gastrointestinal epithelium is a major cause of basal Fe loss. Because intestinal epithelial cells are actually Fe-deficient in $\mathrm{HH}$, basal loss among homozygotes may be lower than in normal individuals. However, because there are no data available, basal loss of homozygotes was still assumed to be $14 \mu \mathrm{g} / \mathrm{kg}$ per $\mathrm{d}^{(30)}$. Average daily loss was calculated according to body weight and Fe loss per unit body weight. For women of reproductive age in the cohort, the amount of menstrual blood loss per menstrual cycle was assigned based on an empirical distribution ${ }^{(29)}$. The amount of Fe lost each month during menstruation was calculated based on the amount of blood loss and $\mathrm{Hb}$ level. By the end of each month, storage Fe was updated, taking into account $\mathrm{Fe}$ absorption and Fe loss during the month. Consequently, the SF level was updated corresponding to the new amount of storage Fe.

\section{Annual updating}

Events simulated on an annual interval include blood donations and pregnancy. Pregnancy was simulated as an event happening within a given simulation year. Fe loss during pregnancy was based on experts' judgement ${ }^{(26-28,42)}$. The most commonly used distribution to quantify experts' opinions, triangle distribution, was applied. The small loss of Fe from breast milk was neglected. The probabilities of giving birth were estimated from national vital statistics and varied according to mother's age ${ }^{(31)}$. Fe supplement usage during pregnancy, the length of taking supplements and the amount of Fe taken were simulated based on data from NHANES III. NHANES III data were also used to calculate the probability of being a blood donor for each age and gender group and the frequency of blood donation each year. For blood donors in the simulation model, Fe loss through blood donation was calculated using frequency of blood donation per year, units of blood donated each time and $\mathrm{Hb}$ level.

At the end of each simulation year, TBI, Hb and SF levels were updated as the result of these events. Distributions of total body Fe were recalculated following the rule that $\mathrm{Fe}$ in the body is used to build tissue and maintain normal $\mathrm{Hb}$ level first, and then extra Fe will be stored $^{(43)}$. Fe in the body was first allocated to body tissues, then to maintain a normal Hb level. Only after meeting these two needs was the remaining Fe apportioned to storage. If the amount of TBI was insufficient to maintain a normal $\mathrm{Hb}$ level, the highest $\mathrm{Hb}$ level possible was calculated.

Mortality rates were obtained from national vital statistics reports. The mortality rates for different gender, age and ethnic groups in 1994 were used in the model ${ }^{(32)}$. Based on these rates, mortality in various subgroups was randomly assigned.

\section{Dietary modification}

The simulation outcomes were the percentage of the cohort with TBI $>10 \mathrm{~g}, \mathrm{TBI}>15 \mathrm{~g}$ and $\mathrm{TBI}>20 \mathrm{~g}$. Among normal individuals, TBI is less than $5 \mathrm{~g}^{(28)}$. Twenty grams of TBI is usually thought to be a threshold related to specific clinical manifestation among homozygotes for HFE gene mutation ${ }^{(44)}$; however, the implications of mild or moderate TBI levels are still in debate. The percentages of the cohort with $\mathrm{TBI}>10 \mathrm{~g}, \mathrm{TBI}>15 \mathrm{~g}$ and $\mathrm{TBI}>20 \mathrm{~g}$ were used to illustrate the number of individuals in the cohort with various degrees of Fe overload.

Dietary modification was designed based on the recommended dietary allowance (RDA) for each age and gender group $^{(30)}$. In the first intervention, if an individual's food Fe intake was $>200 \%$ of the RDA for his/her gender and age group, his/her Fe intake was reduced to $200 \%$ RDA by decreasing non-haem Fe intake; if an individual's food $\mathrm{Fe}$ intake was already $\leq 200 \% \mathrm{RDA}$, no dietary modification was made. Similarly, in another intervention tested, each individual's Fe intake from food was capped to $100 \%$ RDA. To test the efficacy of the interventions, $100 \%$ compliance with dietary modification was assumed. Fe defortification was also tested. The percentages of individuals with various degrees of Fe overload under different dietary interventions were compared.

\section{Sensitivity analysis}

Because absorption of non-haem Fe is a critical assumption in the model, sensitivity analysis was performed to determine its impact on the simulation outcome. 
When analysing data from feeding studies among homozygotes of $\mathrm{HH}$, a linear relationship was used to describe the relationship between non-haem Fe absorption rate and SF level ${ }^{(19,21)}$. The equation was:

$$
\log (\text { non-haem Fe absorption rate })=\alpha-\beta \times \mathrm{SF}+\varepsilon .
$$

Slope $\beta$ reflects the average feedback control of $\mathrm{Fe}$ absorption by Fe status. When data from feeding studies were analysed $^{(19,21)}$, the estimated slope was $\beta_{1}=0 \cdot 0004$, which was used to build the main simulation model. Since the subjects used in these feeding studies may be a selective subgroup of homozygotes whose feedback control of Fe absorption was likely to be more severely damaged than those who had not developed $\mathrm{HH}$, three steeper slopes were arbitrarily chosen $\left(\beta_{2}=0 \cdot 0005\right.$, $\beta_{3}=0.0008$ and $\beta_{4}=0.002$ ) and used for sensitivity analysis. If, for a woman with wild genotype and $500 \mathrm{mg}$ Fe storage, the non-haem Fe absorption rate is $5 \%$ for a certain meal, Fig. 2 shows the average non-haem Fe absorption rate for homozygotes by SF level for the same meal under different slope assumptions.

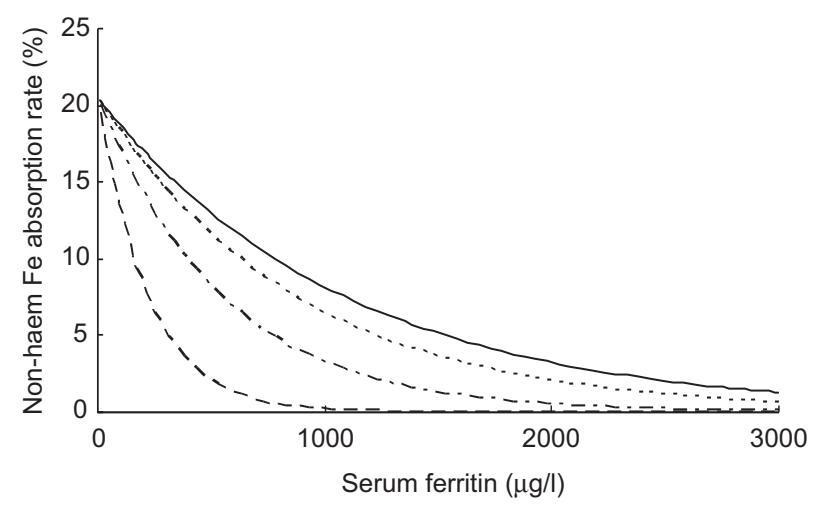

Fig. 2 Average non-haem iron absorption rates under different slope assumptions $\left(-, \beta_{1}=0.0004 ;---, \beta_{2}=0.0005 ;----\right.$, $\left.\beta_{3}=0.0008 ;---, \beta_{4}=0.002\right)$
Simulations were run under different slope assumptions and the percentages of the cohort with $\mathrm{TBI}>10 \mathrm{~g}, \mathrm{TBI}>$ $15 \mathrm{~g}$ and $\mathrm{TBI}>20 \mathrm{~g}$ were calculated and compared. The effect of capped Fe intake at 100\% RDA on Fe accumulation was tested under different slope assumptions.

\section{Results}

When Fe absorption data from feeding studies were used to build the model $\left(\beta_{1}=0 \cdot 0004\right)$, without dietary change, $66.0 \%$ of the simulation cohort reached $\mathrm{TBI}>10 \mathrm{~g}$, $27 \cdot 8 \%$ of the cohort accumulated $\mathrm{TBI}>15 \mathrm{~g}$ and only $7 \cdot 3 \%$ of the cohort reached $\mathrm{TBI}>20 \mathrm{~g}$ (Fig. 3). Fe defortification or reducing Fe intake to $200 \%$ RDA slightly reduced the speed of $\mathrm{Fe}$ accumulation and their sizes of impact were similar. With stricter dietary change, when Fe intake was capped at $100 \%$ RDA, Fe accumulation was substantially slower and the percentage of the cohort reaching high TBI levels was lower.

Since a majority of those with increased TBI were males, the rate of $\mathrm{Fe}$ accumulation and the impact of different dietary interventions were more obvious when men were analysed separately (Fig. 4).

\section{Sensitivity analysis}

When steeper slopes $(\beta)$ for the regression equation on non-haem Fe absorption and SF were applied, individuals with the same body Fe stores would absorb less Fe from the same meal (Fig. 2). The percentage of individuals who reached $>10 \mathrm{~g},>15 \mathrm{~g}$ and $>20 \mathrm{~g}$ TBI also decreased gradually as the slope changed from $\beta_{1}$ to $\beta_{4}$ (Table 2 ). As the percentage of the cohort with $\mathrm{TBI}>10 \mathrm{~g},>15 \mathrm{~g}$ and $>20$ g decreased under different slope assumptions, the impact of diet on the development of Fe overload also reduced. With slope $\beta_{2}=0 \cdot 0005,4 \cdot 2 \%$ of the cohort reached $\mathrm{TBI}>20 \mathrm{~g}$ in the no intervention model; this

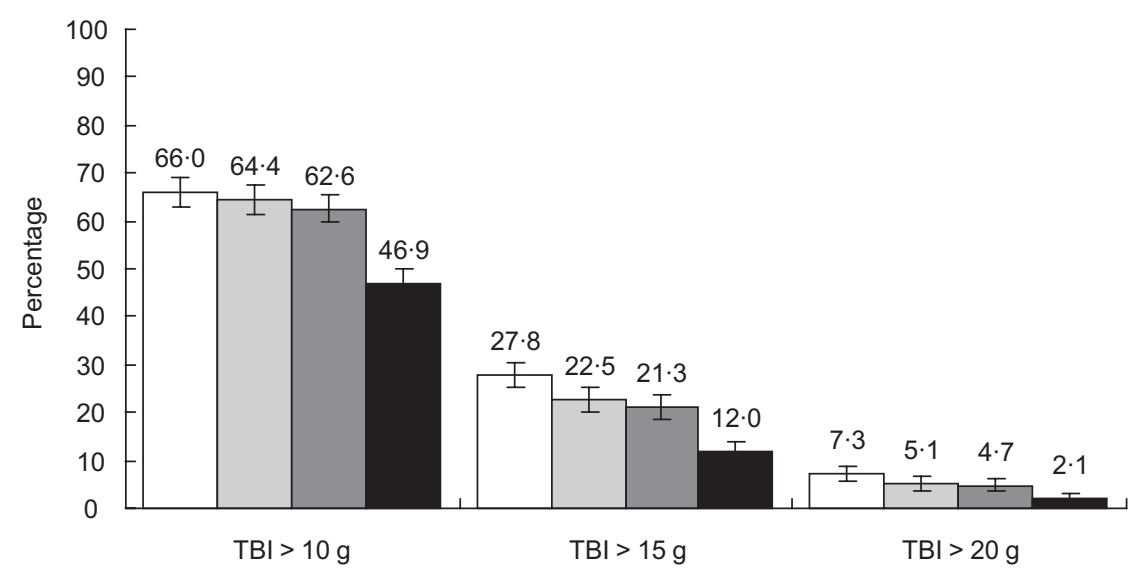

Fig. 3 Percentage of the cohort reaching total body iron (TBI) $>10 \mathrm{~g},>15 \mathrm{~g}$ and $>20 \mathrm{~g}$ under different simulation scenarios ( $\square$, no dietary change; $\square$, dietary iron intake capped at $200 \%$ of the recommended dietary allowance (RDA); $\square$, iron defortification; $\mathbf{\square}$, dietary iron intake capped at $100 \%$ RDA), with $95 \%$ confidence interval represented by vertical bars, in homozygotes for the HFE gene associated with hereditary haemochromatosis 
number decreased to $1 \cdot 1 \%$ when Fe intake was capped at $100 \%$ RDA. When slope $\beta_{3}=0.0008$ was used in the simulation model, the corresponding estimates were $2 \cdot 0 \%$ and $1 \cdot 0 \%$.

\section{Discussion}

Overall, the present simulation results demonstrate that variation in $\mathrm{Fe}$ intake and variation in the damage to the control of Fe absorption among homozygotes contribute to variation in the rate of $\mathrm{Fe}$ accumulation among homozygotes. This suggests that lifelong dietary habits and national fortification policy can affect the rate of $\mathrm{Fe}$ accumulation among homozygotes for $\mathrm{HH}$.

Two knowledge gaps currently prevent us from fully quantifying the exact impact of dietary modification on the health outcomes of homozygotes for HH. First, as sensitivity analysis reveals, the rate of Fe accumulation and the impact of dietary interventions are dependent on assumptions concerning Fe absorption rate, which reflects the severity of damage on the Fe absorption control system. The effect of dietary intervention is strongest among individuals whose $\mathrm{Fe}$ absorption regulation has been impaired significantly, which is very likely to be true among patients who are diagnosed with $\mathrm{HH}$ or individuals with a family history of $\mathrm{HH}$. As the assumed Fe absorption rate (and degree of regulatory impairment) decreases, so does the percentage of adults with Fe overload and the effect of dietary modification. In particular, dietary modification has a smaller effect in reducing severe Fe overload $(\mathrm{TBI}>20 \mathrm{~g})$ but still a modest effect in reducing mild and moderate Fe overload.

These sensitivity analyses are important because our current understanding of the degree of impairment on Fe absorption control is based on feeding studies using patients who were already diagnosed with HH. Such patients may have a higher degree of regulatory impairment than the average for all homozygotes. Feeding studies using more randomly selected homozygotes are needed, including those diagnosed with $\mathrm{HH}$ as well as asymptomatic homozygotes. Such studies would provide a more accurate understanding of the variation in impairment of the Fe absorption control system among homozygotes for $\mathrm{HH}$ and thus more accurate simulation results.

The finding that, under lesser degree of Fe absorption regulatory impairment, dietary modification is more

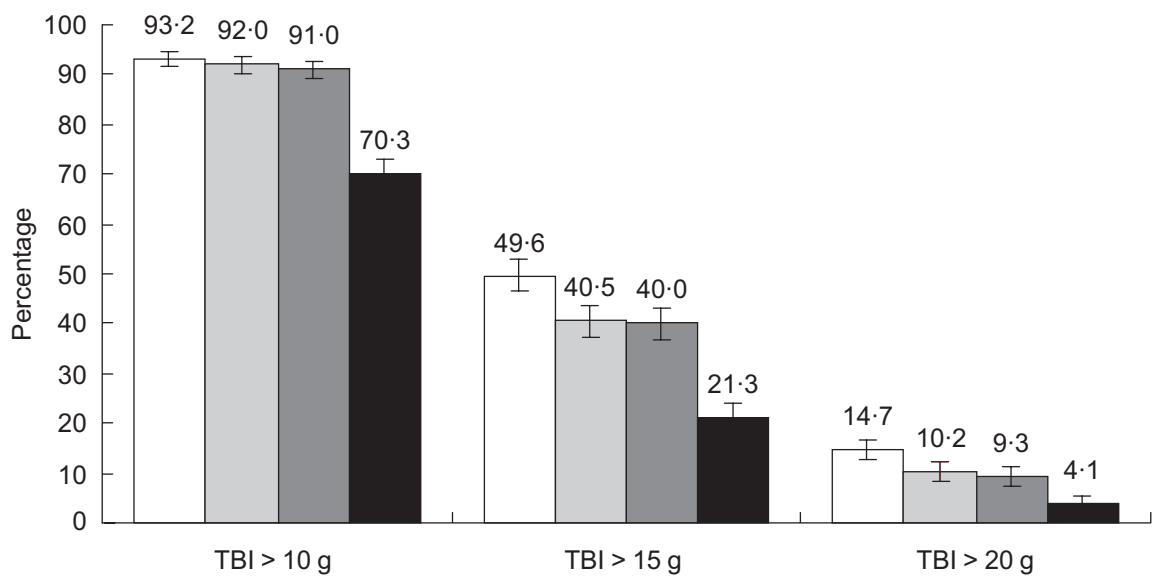

Fig. 4 Percentage of males in the cohort reaching total body iron (TBI) $>10 \mathrm{~g},>15 \mathrm{~g}$ and $>20 \mathrm{~g}$ under different simulation scenarios ( $\square$, no dietary change; $\square$, dietary iron intake capped at $200 \%$ of the recommended dietary allowance (RDA); $\square$, iron defortification; $\mathbf{n}$, dietary iron intake capped at $100 \% \mathrm{RDA}$ ), with $95 \%$ confidence interval represented by vertical bars, in homozygotes for the HFE gene associated with hereditary haemochromatosis

Table 2 Percentages of the cohort reaching certain TBI levels under different iron absorption assumptions in homozygotes for the HFE gene associated with hereditary haemochromatosis

\begin{tabular}{|c|c|c|c|c|c|c|c|c|c|c|c|c|}
\hline & \multicolumn{6}{|c|}{ No dietary change } & \multicolumn{6}{|c|}{ Fe intake $\leq 100 \%$ RDA } \\
\hline & \multicolumn{2}{|c|}{$\mathrm{TBI}>10 \mathrm{~g}$} & \multicolumn{2}{|c|}{$\mathrm{TBI}>15 \mathrm{~g}$} & \multicolumn{2}{|c|}{$\mathrm{TBI}>20 \mathrm{~g}$} & \multicolumn{2}{|c|}{$\mathrm{TBI}>10 \mathrm{~g}$} & \multicolumn{2}{|c|}{$\mathrm{TBI}>15 \mathrm{~g}$} & \multicolumn{2}{|c|}{$\mathrm{TBI}>20 \mathrm{~g}$} \\
\hline & $\%$ & $95 \% \mathrm{Cl}$ & $\%$ & $95 \% \mathrm{Cl}$ & $\%$ & $95 \% \mathrm{Cl}$ & $\%$ & $95 \% \mathrm{Cl}$ & $\%$ & $95 \% \mathrm{Cl}$ & $\%$ & $95 \% \mathrm{Cl}$ \\
\hline$\beta_{1}$ & $66 \cdot 0$ & $63 \cdot 1,68 \cdot 9$ & $27 \cdot 8$ & $25 \cdot 0,30 \cdot 6$ & $7 \cdot 3$ & $5 \cdot 7,8 \cdot 9$ & $46 \cdot 9$ & $43 \cdot 9,49 \cdot 9$ & $12 \cdot 0$ & $10 \cdot 0,14 \cdot 0$ & $2 \cdot 1$ & $1 \cdot 2,2 \cdot 9$ \\
\hline$\beta_{2}$ & $58 \cdot 0$ & $54 \cdot 9,61 \cdot 1$ & $18 \cdot 0$ & $15 \cdot 6,20 \cdot 4$ & $4 \cdot 2$ & $3 \cdot 0,5 \cdot 4$ & $37 \cdot 9$ & $37 \cdot 3,38 \cdot 5$ & $7 \cdot 7$ & $4 \cdot 7,10 \cdot 7$ & $1 \cdot 1$ & $0 \cdot 4,1 \cdot 7$ \\
\hline$\beta_{3}$ & $49 \cdot 7$ & $46 \cdot 6,52 \cdot 8$ & $12 \cdot 5$ & $10 \cdot 5,14 \cdot 6$ & $2 \cdot 0$ & $1 \cdot 1,2 \cdot 9$ & 31.5 & $30 \cdot 9,32 \cdot 1$ & $5 \cdot 7$ & $2 \cdot 8,8 \cdot 6$ & $1 \cdot 0$ & $0 \cdot 4,1 \cdot 6$ \\
\hline$\beta_{4}$ & $10 \cdot 0$ & $8 \cdot 1,11 \cdot 9$ & $2 \cdot 7$ & $1 \cdot 7,3 \cdot 7$ & 0.6 & $0 \cdot 1,1 \cdot 1$ & $8 \cdot 3$ & $7 \cdot 8,8 \cdot 8$ & $2 \cdot 2$ & $0.5,3.9$ & 0.6 & $0 \cdot 1,1 \cdot 1$ \\
\hline
\end{tabular}

$\mathrm{TBI}$, total body Fe; RDA, recommended dietary allowance. 
efficacious in reducing mild and moderate Fe overload (compared with severe overload) is potentially significant. This is because mild and moderate Fe overload is far more common than is severe overload. However, the public health implications of this remain unclear because studies of the relationship between mild to moderate Fe overload and the risk of chronic diseases have not produced consistent findings. Some studies found no increased risk for chronic diseases among adults with mild to moderate Fe overload ${ }^{(45-48)}$, but others reached the opposite conclusion ${ }^{(49-51)}$. More prospective studies looking at the risk of chronic diseases caused by mild to moderate Fe overload are needed.

In principle, dietary modification might be achieved by changing diet habits among homozygotes for $\mathrm{HH}$. This intervention is targeted so individuals without such genetic mutation will not be impacted. To estimate the efficacy of this intervention, we assumed $100 \%$ compliance in our simulation study. In reality, the effectiveness of the intervention also relies on the compliance to both genetic screening test and dietary change. Fe defortification operates at the population level, so the issue of compliance is not involved. However, defortification may have an unwanted impact on other segments of the population who are at risk of Fe deficiency. For instance, the prevalence of Fe deficiency increased among school girls in Sweden after Fe fortification of flour was halted ${ }^{(52)}$. Similarly, in our simulations of the general US population we estimated that defortification may increase Fe-deficiency anaemia among 3-5-year-olds and women aged $20-49$ years ${ }^{(53)}$.

In summary, the present study provides the first available evidence that variation in dietary $\mathrm{Fe}$ intake by homozygotes for $\mathrm{HH}$ does affect the rate of total body $\mathrm{Fe}$ accumulation over the course of several decades and that dietary interventions can slow this accumulation. None the less, the public health implications of this finding remain unclear because of generally poor compliance with dietary modifications and continued uncertainty concerning the health effects of mild or moderate Fe overload. Microsimulations of the type employed here can play an increasingly important role in guiding policy choices for conditions like $\mathrm{HH}$ that require decades to develop and may be too difficult or expensive to study through primary intervention trials.

\section{Acknowledgements}

M.T. was funded by a scholarship from the Division of Nutritional Sciences, Cornell University. The current work was partly funded by an unrestricted education grant to Cornell University by the Merck Company Foundation, the philanthropic arm of Merck \& Co. Inc. The authors declare no conflicts of interest. Among the two authors listed here, D.P. conceived of the study and supervised all aspects of its implementation. M.T. completed the analyses and led the writing. Both authors helped to conceptualize ideas, interpret findings and review drafts of the manuscript.

\section{References}

1. Hanson EH, Imperatore G \& Burke W (2001) HFE gene and hereditary hemochromatosis: a HuGE review. Human Genome Epidemiology. Am J Epidemiol 154, 193-206.

2. Steinberg KK, Cogswell ME, Chang JC, Caudill SP, McQuillan GM, Bowman BA, Grummer-Strawn LM, Sampson EJ, Khoury MJ \& Gallagher ML (2001) Prevalence of C282Y and $\mathrm{H} 63 \mathrm{D}$ mutations in the hemochromatosis (HFE) gene in the United States. JAMA 285, 2216-2222.

3. Milman N, Koefoed P, Pedersen P, Nielsen FC \& Eiberg H (2003) Frequency of the HFE C282Y and H63D mutations in Danish patients with clinical haemochromatosis initially diagnosed by phenotypic methods. Eur J Haematol 71, 403-407.

4. El-Serag HB, Inadomi JM \& Kowdley KV (2000) Screening for hereditary hemochromatosis in siblings and children of affected patients. A cost-effectiveness analysis. Ann Intern Med 132, 261-269.

5. Adams PC (1999) Population screening for hemochromatosis. Hepatology 29, 1324-1327.

6. Adams PC, Kertesz AE \& Valberg LS (1995) Screening for hemochromatosis in children of homozygotes: prevalence and cost-effectiveness. Hepatology 22, 1720-1727.

7. Adams PC, Speechley M \& Kertesz AE (1991) Long-term survival analysis in hereditary hemochromatosis. Gastroenterology 101, 368-372.

8. Niederau C, Fischer R, Sonnenberg A, Stremmel W, Trampisch HJ \& Strohmeyer G (1985) Survival and causes of death in cirrhotic and in noncirrhotic patients with primary hemochromatosis. N Engl J Med 313, 1256-1262.

9. Milder MS, Cook JD, Stray S \& Finch CA (1980) Idiopathic hemochromatosis, an interim report. Medicine (Baltimore) 59, 34-49.

10. Adams PC, Kertesz AE \& Valberg LS (1991) Clinical presentation of hemochromatosis: a changing scene. Am J Med 90, 445-449.

11. Niederau C, Fischer R, Purschel A, Stremmel W, Haussinger D \& Strohmeyer G (1996) Long-term survival in patients with hereditary hemochromatosis. Gastroenterology 110, 1107-1119.

12. Beutler E, Felitti VJ, Koziol JA, Ho NJ \& Gelbart T (2002) Penetrance of $845 \mathrm{G} \rightarrow \mathrm{A}(\mathrm{C} 282 \mathrm{Y})$ HFE hereditary haemochromatosis mutation in the USA. Lancet 359, 211-218.

13. McCune CA, Al-Jader LN, May A, Hayes SL, Jackson HA \& Worwood M (2002) Hereditary haemochromatosis: only $1 \%$ of adult HFEC282Y homozygotes in South Wales have a clinical diagnosis of iron overload. Hum Genet 111, 538-543.

14. Bulaj ZJ, Ajioka RS, Phillips JD, LaSalle BA, Jorde LB, Griffen LM, Edwards CQ \& Kushner JP (2000) Diseaserelated conditions in relatives of patients with hemochromatosis. N Engl J Med 343, 1529-1535.

15. Pietrangelo A (2004) Hereditary hemochromatosis - a new look at an old disease. N Engl J Med 350, 2383-2397.

16. Asberg A, Hveem K, Thorstensen K, Ellekjter E, Kannelonning K, Fjosne U, Halvorsen TB, Smethurst HB, Sagen E \& Bjerve KS (2001) Screening for hemochromatosis: high prevalence and low morbidity in an unselected population of 65,238 persons. Scand J Gastroenterol 36, 1108-1115.

17. Beutler E (2003) The HFE Cys282Tyr mutation as a necessary but not sufficient cause of clinical hereditary hemochromatosis. Blood 101, 3347-3350. 
18. Crawford DH, Powell LW \& Halliday JW (1996) Factors influencing disease expression in hemochromatosis. Annu Rev Nutr 16, 139-160.

19. Bezwoda WR, Disler PB, Lynch SR, Charlton RW, Torrance JD, Derman D, Bothwell TH, Walker RB \& Mayet F (1976) Patterns of food iron absorption in iron-deficient white and Indian subjects and in venesected haemochromatotic patients. BrJ Haematol 33, 425-436.

20. Bezwoda WR, Bothwell TH, Derman DP, MacPhail AP, Torrance JD \& Charlton RW (1981) Effect of diet on the rate of iron accumulation in idiopathic haemochromatosis. S Afr Med J 59, 219-222.

21. Lynch SR, Skikne BS \& Cook JD (1989) Food iron absorption in idiopathic hemochromatosis. Blood 74, 2187-2193.

22. Olsson KS, Vaisanen M, Konar J \& Bruce A (1997) The effect of withdrawal of food iron fortification in Sweden as studied with phlebotomy in subjects with genetic hemochromatosis. Eur J Clin Nutr 51, 782-786.

23. Milder MS, Cook JD \& Finch CA (1978) Influence of food iron absorption on the plasma iron level in idiopathic hemochromatosis. Acta Haematol 60, 65-75.

24. Barton JC, McDonnell SM, Adams PC, Brissot P, Powell LW, Edwards CQ, Cook JD \& Kowdley KV (1998) Management of hemochromatosis. Hemochromatosis Management Working Group. Ann Intern Med 129, 932-939.

25. Berner LA, Clydesdale FM \& Douglass JS (2001) Fortification contributed greatly to vitamin and mineral intakes in the United States, 1989-1991. J Nutr 131, 2177-2183.

26. Food and Nutrition Board, Institute of Medicine (1990) Nutrition During Pregnancy. Washington, DC: National Academy Press.

27. Bothwell TH (2000) Iron requirements in pregnancy and strategies to meet them. Am J Clin Nutr 72, Suppl., 257S-264S

28. Bothwell TH, Charlton RW, Cook JD \& Finch CA (1979) Iron Metabolism in Man. St. Louis, MO: Blackwell Scientific Publications.

29. Hallberg L, Hogdahl AM, Nilsson L \& Rybo G (1966) Menstrual blood loss - a population study. Variation at different ages and attempts to define normality. Acta Obstet Gynecol Scand 45, 320-351.

30. Food and Nutrition Board, Institute of Medicine (2000) Dietary Reference Intakes for Vitamin A, Vitamin K, Arsenic, Boron, Chromium, Copper, Iodine, Iron, Manganese, Molybdenum, Nickel, Silicon, Vanadium, and Zinc. Washington, DC: National Academies Press.

31. Ventura SJ, Mosher WD, Curtin SC, Abma JC \& Henshaw S (2000) Trends in pregnancies and pregnancy rates by outcome: estimates for the United States, 1976-96. Vital Health Stat 21 issue 56, 1-47.

32. National Center for Health Statistics (2000) Death rates for selected causes by 10-year age groups, race and sex in the Unites States, 1979-98. http://www.cdc.gov/nchs/datawh/ statab/unpubd/mortabs/hist290.htm (accessed February 2007).

33. Nadler SB, Hidalgo J \& Bloch T (1962) Prediction of blood volume in normal human adults. Surgery 51, 224-232.

34. Mollison P (1983) Blood Transfusion in Clinical Medicine. Boston, MA: Blackwell Scientific Publications.

35. Hidalgo JU, Nadler SB \& Bloch $\mathrm{T}$ (1962) The use of electronic digital computer to determine best fit of blood volume formulas. J Nucl Med 3, 94-99.

36. Sham RL, Ou CY, Cappuccio J, Braggins C, Dunnigan K \& Phatak PD (1997) Correlation between genotype and phenotype in hereditary hemochromatosis: analysis of 61 cases. Blood Cells Mol Dis 23, 314-320.
37. Bassett ML, Halliday JW, Ferris RA \& Powell LW (1984) Diagnosis of hemochromatosis in young subjects: predictive accuracy of biochemical screening tests. Gastroenter$\operatorname{ology} \mathbf{8 7}, 628-633$.

38. Beutler E, Felitti V, Ho NJ \& Gelbart T (2002) Relationship of body iron stores to levels of serum ferritin, serum iron, unsaturated iron binding capacity and transferrin saturation in patients with iron storage disease. Acta Haematol 107, $145-149$.

39. Food and Nutrition Board, National Research Council (1986) Nutrient Adequacy: Assessment Using Food Consumption Surveys. Washington, DC: National Academy Press.

40. Monsen ER \& Balintfy JL (1982) Calculating dietary iron bioavailability: refinement and computerization. J Am Diet Assoc 80, 307-311.

41. Hallberg L, Brune M, Erlandsson M, Sandberg AS \& Rossander-Hulten L (1991) Calcium: effect of different amounts on nonheme- and heme-iron absorption in humans. Am J Clin Nutr 53, 112-119.

42. Hallberg L (1988) Iron balance in pregnancy. In Vitamins and Minerals in Pregnancy and Lactation, pp. 115-127 [H Berger, editor]. New York: Vevey/Raven Press Ltd.

43. Brock JH, Pippard MJ \& Powell LW (1994) Iron Metabolism in Health and Disease. Philadelphia, PA: W.B. Saunders Company Ltd.

44. Lynch SR (1995) Iron overload: prevalence and impact on health. Nutr Rev 53, 255-260.

45. Shizukuda Y, Bolan CD, Tripodi DJ et al. (2006) Left ventricular systolic function during stress echocardiography exercise in subjects with asymptomatic hereditary hemochromatosis. Am J Cardiol 98, 694-698.

46. Yunker LM, Parboosingh JS, Conradson HE et al. (2006) The effect of iron status on vascular health. Vasc Med $\mathbf{1 1}$, 85-91.

47. Waalen J, Felitti V, Gelbart T, Ho NJ \& Beutler E (2002) Prevalence of coronary heart disease associated with HFE mutations in adults attending a health appraisal center. Am J Med 113, 472-479.

48. Chan AT, Ma J, Tranah GJ, Giovannucci EL, Rifai N, Hunter DJ \& Fuchs CS (2005) Hemochromatosis gene mutations, body iron stores, dietary iron, and risk of colorectal adenoma in women. J Natl Cancer Inst 97, 917-926.

49. Acton RT, Barton JC, Passmore LV et al. (2006) Relationships of serum ferritin, transferrin saturation, and HFE mutations and self-reported diabetes in the Hemochromatosis and Iron Overload Screening (HEIRS) study. Diabetes Care 29, 2084-2089.

50. Wolff B, Volzke H, Ludemann J, Robinson D, Vogelgesang D, Staudt A, Kessler C, Dahm JB, John U \& Felix SB (2004) Association between high serum ferritin levels and carotid atherosclerosis in the study of health in Pomerania (SHIP). Stroke 35, 453-457.

51. Mendler MH, Turlin B, Moirand R, Jouanolle AM, Sapey T, Guyader D, Le Gall JY, Brissot P, David V \& Deugnier Y (1999) Insulin resistance-associated hepatic iron overload. Gastroenterology 117, 1155-1163.

52. Hulthén L \& Halberg L (2005) Increased prevalence of iron deficiency due to withdrawal of iron fortification of flour in Sweden. In Reports of the 2004 International Nutritional Anemia Consultative Group Symposium, p. 63. Washington, DC: ILSI Human Nutrition Institute.

53. Tao M, Pelletier DL \& Milder DD (2007) The potential effect of iron defortification on iron-deficiency anaemia in the US population. Public Health Nutr 10, 1266-1273. 